\title{
ANALISIS KEPUASAN NASABAH ATAS KUALITAS LAYANAN INTERNET BANKING PADA PT BANK PEMBANGUNAN DAERAHJAWA TENGAH KANTOR CABANG PATI
}

\author{
Anita Elvi Mutiasari*) \\ Embun Duriany Soemarso**) \\ *) nittamutiasari@gmail.com
}

\begin{abstract}
This research aims to identify how to increase customer satisfaction of internet banking service quality at PT Bank Pembangunan Daerah Jawa Tengah Pati Branch Office with five dimensions of service quality which were tangible, reliability, responsiveness, assurance, and empathy.

In this research, the sampling technique used was purposive sampling technique. The data in this research were obtained from observations and distributing questionnaires to 100 respondents. Data analysis methods used are validity test, reliability test, satisfaction index test, satisfaction gap test and satisfaction mapping with cartesian diagram.

Based on the result of the validity and reliability test, the indicators like tangible, reliability, responsiveness, assurance and empathy are valid and reliable. Based on the result of the satisfaction index analysis, the weighting score of internet banking quality service is 4,219. That score is between 3,43 - 4,23 wich means Satisfied. Based on the result of the satisfaction gap test the increase of satisfaction established on the fourteen sub-indicators show satisfaction, and four sub-indicators show dissatisfaction. Meanwhile, when viewed from the cartesian diagram mapping result, there are four indicators that fall into the quadrant I, four indicators in the quadrant II, four indicators in the quadrant III, and six indicators in the quadrant IV.
\end{abstract}

Keywords: Customer Satisfaction, Service Quality, and Internet Banking

*) Mahasiswa Tugas Akhir Prodi Keuangan dan Perbankan, Jurusan Akuntansi, Politeknik Negeri Semarang

**) Dosen Jurusan Akuntansi Politeknik Negeri Semarang

\section{PENDAHULUAN}

\section{Latar Belakang}

Dalam kegiatan industri modern saat ini, tingkat mobilitas dan kesibukan yang semakin meningkat mengakibatkan banyak orang membutuhkan alat yang bisa dengan cepat dan tepat dalam pemenuhan kebutuhan mereka. Salah satunya adalah sektor industri perbankan. Perkembangan teknologi informasi, telekomunikasi, dan internet menyebabkan mulai munculnya aplikasi bisnis yang berbasis internet. Salah satu aplikasi yang mulai mendapat perhatian adalah internet banking. Saat ini perbankan di Indonesia tengah berlomba-lomba dalam kemajuan di bidang teknologi. Kemajuan di bidang teknologi ini akan mempermudah nasabah untuk bertransaksi dimanapun mereka berada tanpa perlu harus mengantre panjang untuk melakukan transaksi dengan kecanggihan teknologi yang ada saat ini yaitu dengan bertransaksi melalui internet banking (Helza Vebrika ST (2007) dalam Rusdianti, dkk $(2016: 22))$. 
Sebagai salah satu bentuk layanan dan juga sebagai alat strategi bersaing, maka tujuan akhir penggunaan internet banking adalah untuk memuaskan nasabah. Oleh karena itu, kepuasan nasabah dalam menggunakan fasilitas internet banking perlu dievaluasi serta diidentifikasi faktor-faktor penentunya. Pemahaman terhadap faktor-faktor penentu kepuasan nasabah internet banking akan memberikan informasi empiris yang berguna bagi manajemen bank guna meningkatkan kualitas layanannya kepada nasabah (Hartawan, 2017:151).

Keberhasilan perusahaan dalam memberikan jasa yang berkualitas kepada pelanggannya, pencapaian pangsa pasar, dan peningkatan laba perusahaan tersebut sangat ditentukan oleh pendekatan yang digunakan (Zeithaml dkk., (1996) dalam Lupiyoadi, 2013:216). Salah satu pendekatan kualitas jasa yang banyak digunakan adalah dengan model SERVQUAL (Service Quality) yang dikembangkan oleh Parasuraman et.al. (1998) dalam Lupiyoadi (2013:216) yang meliputi Berwujud (Tangible), Kehandalan (Reliability), Ketanggapan (Responsiveness), Jaminan (Assurance) serta Empati (Empathy).

PT Bank Pembangunan Daerah Jawa Tengah merupakan salah satu bank milik pemerintah yang tersebar di Jawa Tengah, dan berkantor pusat di Semarang. Berdasarkan Akta Perubahan Anggaran Dasar No.68 tanggal 7 Mei 2005 Notaris Prof. DR. Liliana Tedjosaputro dan Surat Keputusan Menteri Hukum dan Hak Asasi Manusia No. C.17331 HT.01.04.TH.2005 tanggal 22 Juni 2005, maka nama sebutan (call name) PT. Bank Pembangunan Daerah Jawa Tengah berubah dari sebelumnya Bank BPD Jateng menjadi Bank Jateng.

Bank Jateng sadar betul pesatnya perkembangan teknologi sudah tidak dapat dipungkiri lagi. Berbagai macam kemudahan dalam mengakses suatu informasi sudah dapat dinikmati oleh masyarakat lewat internet. Maka Bank Jateng meluncurkan internet banking pada tahun 2018, hal ini berarti internet banking Bank Jateng masih tergolong sangat baru. Berdasarkan hasil penelitian melalui survei yang dilakukan oleh Marketing Research Indonesia (MRI) dalam Bank Service Excellence Monitor (BSEM) periode Mei 2018, menunjukkan performa internet banking 2 BPD dalam Tabel 1.1 berikut:

Tabel 1 Performa Internet Banking 2 BPD Tahun 2018

\begin{tabular}{|c|l|c|}
\hline No. & \multicolumn{1}{|c|}{ Bank } & Jumlah (\%) \\
\hline 1 & Bank Sumsel Babel & 86,46 \\
\hline 2 & Bank Jatim & 80,75 \\
\hline
\end{tabular}

Sumber: Majalah Infobank Mei 2018

Berdasarkan Tabel 1 menunjukkan bahwa Bank Sumsel Babel mempunyai internet banking yang baik dengan jumlah (\%) yaitu 86,46 \% sedangkan Bank Jatim yaitu 80,75 \%. Bank Jateng belum masuk dalam tabel tersebut, dikarenakan internet banking Bank Jateng masih tergolong baru yakni baru diluncurkan pada tahun 2018. 
Meskipun internet banking Bank Jateng masih tergolong baru, tetapi sudah ada keluhankeluhan dari nasabah terhadap pelayanan internet banking Bank Jateng. Layanan ini masih menimbulkan masalah yang menyebabkan nasabah kecewa akan pelayanannya. Berikut ini merupakan pernyataan-pernyataan yang menyatakan masalah internet banking Bank Jateng yang terdapat pada Tabel 2.

Tabel 2 Keluhan Nasabah Internet Banking Bank Jateng Kantor Cabang Pati

\begin{tabular}{|c|c|}
\hline Pra Sumber & Keluhan Nasabah \\
\hline \multirow[t]{2}{*}{$\begin{array}{lrr}\text { Data Primer } & \text { Nasabah } \\
\text { Bank Jateng } & \text { Kantor } \\
\text { Cabang Pati } & \end{array}$} & $\begin{array}{l}\text { Nasabah Bank Jateng Kantor Cabang Pati menyatakan } \\
\text { bahwa kecepatan layanan internet banking tidak } \\
\text { memuaskan, gangguan sering terjadi. }\end{array}$ \\
\hline & $\begin{array}{l}\text { Nasabah Bank Jateng Kantor Cabang Pati menyatakan } \\
\text { bahwa transfer melalui internet banking Bank Jateng } \\
\text { terkadang eror, transaksi gagal namun saldo sudah } \\
\text { terpotong. }\end{array}$ \\
\hline & $\begin{array}{l}\text { Nasabah Bank Jateng Kantor Cabang Pati menyatakan } \\
\text { bahwa call centre Bank Jateng kurang serius dalam } \\
\text { menjawab dan menangapi apa yang dikeluhkan nasabah } \\
\text { atas layanan internet banking. }\end{array}$ \\
\hline
\end{tabular}

Sumber: Data Sekunder yang diolah (2019)

Tabel 2 menggambarkan fenomena bisnis yang merupakan keluhan-keluhan nasabah yang dapat menyebabkan permasalahan bagi pihak bank. Buruknya kualitas layanan dari bank ini dapat mempengaruhi kepuasan nasabah bank tersebut. Hal ini menjadi penanda bahwa Bank Jateng masih harus mengadakan evaluasi dan memperbaiki kinerjanya untuk meningkatkan kepuasan nasabahnya.

Berdasarkan pemaparan latar belakang di atas penulis tertarik mengkaji topik kepuasan nasabah atas kualitas layanan internet banking Bank Jateng dengan judul "Analisis Kepuasan Nasabah Atas Kualitas Layanan Internet Banking pada PT Bank Pembangunan Daerah Jawa Tengah Kantor Cabang Pati”.

\section{KAJIAN TEORI}

\section{Internet Banking}

Internet banking merupakan pelayanan jasa bank yang memungkinkan nasabah untuk memperoleh informasi, melakukan komunikasi-komunikasi dan melakukan transaksi perbankan melalui jaringan internet, dan bukan merupakan bank yang hanya menyelenggarakan layanan perbankan melalui internet (Bank Indonesia, 2004).

\section{Kepuasan Pelanggan}

Kata kepuasan (satisfaction) berasal dari bahasa latin satis yang berarti cukup baik, memadai dan facio berarti melakukan atau membuat. Kepuasan bisa diartikan sebagai upaya 
pemenuhan sesuatu (Tjiptono, 2004:146). Menurut Enggel (1990:1996) dalam Supranto (2003:396), kepuasan merupakan evaluasi purna beli dimana alternatif yang dipilih sekurangkurangnya memberikan hasil (outcome) sama atau melampaui harapan pelanggan, sedangkan ketidakpuasan timbul apabila hasil yang diperoleh tidak memenuhi harapan pelanggan.

\section{Kualitas Layanan}

Kualitas layanan adalah model yang menggambarkan kondisi nasabah dalam membentuk harapan akan layanan dan pengalaman masa lalu, promosi dari mulut ke mulut, dan iklan dengan membandingkan pelayanan yang mereka harapkan dengan apa yang mereka terima/ rasakan (Kotler, 2009:38).

\section{Dimensi Kualitas Layanan}

Parasuraman, dkk (1998) dalam Lupiyoadi (2013:216) menerangkan bahwa terdapat lima dimensi kualitas layanan yang biasa disebut dengan SERVQUAL sebagai berikut:

\section{Berwujud (Tangible)}

Berwujud (tangible) yaitu kemampuan suatu perusahaan dalam menunjukkan eksistensinya kepada pihak eksternal. Penampilan dan kemampuan sarana dan prasarana fisik perusahaan yang dapat diandalkan keadaan lingkungan sekitarnya merupakan bukti nyata dari pelayanan yang diberikan oleh pemberi jasa. Sub indikator pembentuk indikator berwujud (tangible) merujuk pada penelitian terdahulu yang dikembangkan dalam penelitian ini, yaitu sebagai berikut:

$\mathrm{X}_{1.1} \quad$ : Mudah untuk masuk pada portal website internet banking Bank Jateng, (Kurniasari, 2016:8).

$\mathrm{X}_{1.2}$ : Tampilan website internet banking Bank Jateng didesain secara jelas, menarik dan informatif, (Huda dan Wahyuni, 2013:246).

$\mathrm{X}_{1.3}$ : Website internet banking Bank Jateng menyediakan bahasa yang mudah untuk dimengerti, (Kurniasari, 2016:8).

$\mathrm{X}_{1.4}$ : Website internet banking Bank Jateng menyediakan iklan dan fitur-fitur yang jelas, (Yusnaini, 2010:7).

\section{Keandalan (Reliability)}

Keandalan (reliability) yaitu kemampuan perusahaan untuk memberikan pelayanan sesuai dengan yang dijanjikan secara akurat dan terpercaya. Sub indikator pembentuk indikator keandalan (reliability) merujuk pada penelitian terdahulu yang dikembangkan dalam penelitian ini, yaitu sebagai berikut:

$\mathrm{X}_{2.1}$ : Informasi dalam website internet banking Bank Jateng akurat, (Huda dan Wahyuni, 2013:246). 
$\mathrm{X}_{2.2}$ : Setiap transaksi layanan internet banking Bank Jateng selalu menerima konfirmasi, (Rusdianti dkk, 2016:234).

$\mathrm{X}_{2.3}$ : Akses layanan internet banking Bank Jateng lancar, (Sutawidjaya dan Heryanto, 2017:53).

\section{Daya Tanggap (Responsiveness)}

Daya tanggap (responsiveness) yaitu suatu kebijakan untuk membantu dan memberikan pelayanan yang cepat (responsif) dan tepat kepada pelanggan, dengan penyampaian informasi yang jelas. Sub indikator pembentuk indikator daya tanggap (responsiveness) merujuk pada penelitian terdahulu yang dikembangkan dalam penelitian ini, yaitu sebagai berikut:

$\mathrm{X}_{3.1}$ : Petugas Bank Jateng tanggap dalam menangani keluhan nasabah internet banking, (Yusnaini, 2010:7).

$\mathrm{X}_{3.2}$ : Prosedur layanan call centre internet banking Bank Jateng jelas dan tidak berbelitbelit, (Yusnaini, 2010:7).

$\mathrm{X}_{3.3}$ : Adanya layanan khusus apabila terjadi masalah dengan internet banking Bank Jateng, (Huda dan Wahyuni, 2013:246).

\section{Jaminan (Assurance)}

Jaminan (assurance) yaitu pengetahuan, kesopan santunan, dan kemampuan para pegawai perusahaan untuk menumbuhkan rasa percaya para pelanggan kepada perusahaan. Sub indikator pembentuk indikator jaminan (assurance) merujuk pada penelitian terdahulu yang dikembangkan dalam penelitian ini, yaitu sebagai berikut:

$\mathrm{X}_{4.1} \quad$ : Sistem internet banking Bank Jateng dilengkapi dengan keamanan yang canggih sehingga pihak bank menjamin kerahasiaan dalam transaksi, (Huda dan Wahyuni, 2013:130).

$\mathrm{X}_{4.2}$ : Petugas call centre internet banking Bank Jateng memiliki sikap yang ramah dan sopan, (Yusnaini, 2010:7).

$\mathrm{X}_{4.3}$ : Kunci pengaman (password) internet banking Bank Jateng tidak mudah terlacak, (Kurniasari, 2016:8).

$\mathrm{X}_{4.4}$ : Bank Jateng memberikan jaminan apabila terjadi kesalahan transaksi di internet banking, (Kurniasari, 2016:8).

\section{Empati (Empathy)}

Empati (empathy) yaitu memberikan perhatian yang tulus dan bersifat individual atau pribadi yang diberikan kepada pelanggan dengan berupaya memahami keinginan konsumen. Sub indikator pembentuk indikator empati (empathy) merujuk pada penelitian terdahulu yang dikembangkan dalam penelitian ini, yaitu sebagai berikut: 
$\mathrm{X}_{5.1} \quad$ : Call centre internet banking Bank Jateng melayani selama 24 jam, (Huda dan Wahyuni, 2013:7).

$\mathrm{X}_{5.2}$ : Menu help tersedia di website internet banking Bank Jateng untuk mempermudah pengguna internet banking, (Yusnaini, 2010:7).

$\mathrm{X}_{5.3}$ : Tersedianya kotak saran di website internet banking Bank Jateng, (Yusnaini, 2010:7).

$\mathrm{X}_{5.4}$ : Bank Jateng menangani masalah internet banking dengan baik, (Yusnaini, 2010:7).

\section{Kerangka Pikir}

Kerangka pemikiran teoritis pada penelitian ini terlihat pada Gambar 1.

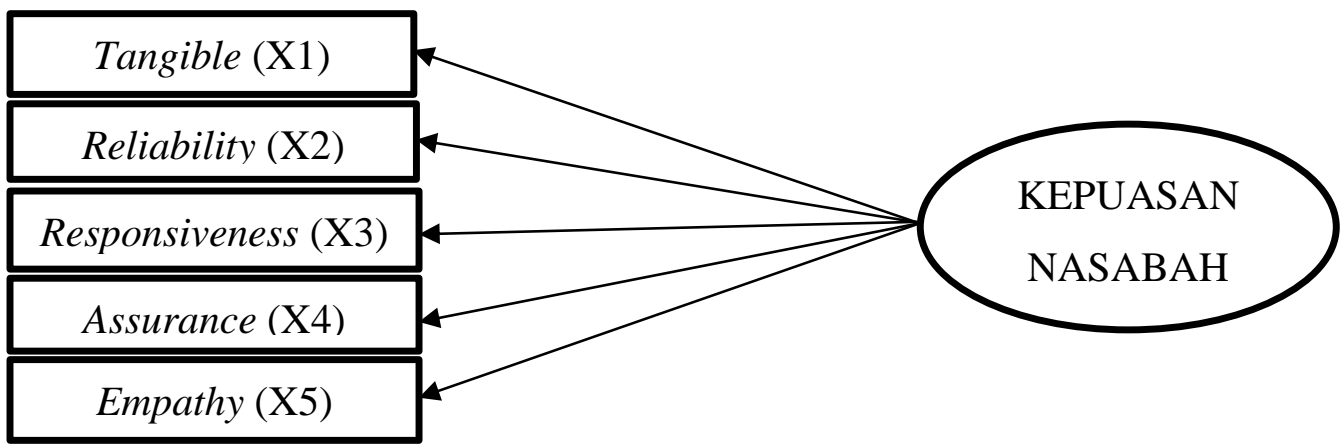

\section{Gambar 1 Kerangka Pemikiran Teoritis}

\section{METODE PENELITIAN}

Jenis penelitian adalah penelitian deskriptif, yaitu penelitian yang terbatas pada usaha mengungkapkan suatu masalah atau keadaan atau peristiwa sebagaimana adanya sehingga bersifat sekesar untuk mengungkapkan fakta. Hasil penelitian ditekankan pada memberikan gambaran secara obyektif tentang keadaan sebenarnya dari obyek yang diselidiki (Hadari, 1991:31).

Populasi dalam penelitian ini adalah para nasabah internet banking Bank Jateng Kantor Cabang Pati. Sedangkan sampel dalam penelitian ini adalah seluruh nasabah internet banking Bank Jateng Kantor Cabang Pati yang telah melakukan transaksi menggunakan internet banking minimal 1 kali dalam 1 bulan, dengan jumlah 100 responden. Teknik pengambilan sampel yang digunakan dalam penelitian ini adalah pendekatan Non probability Sampling. Jenis atau metode sampel yang digunakan yaitu Purposive Sampling.

Untuk memperoleh informasi yang menyangkut karakteristik atau sifat-sifat dari berbagai elemen yang diteliti, teknik pengumpulan data yang digunakan yaitu: 1. Kuesioner merupakan teknik pengumpulan data yang dilakukan dengan cara memberi seperangkat pertanyaan atau pernyataan tertulis kepada responden untuk dijawab (Sugiyono, 2008). 2. Wawancara merupakan teknik pengambilan data yang dilakukan dengan mengadakan tanya jawab langsung dengan pihak-pihak yang menjadi sumber data penelitian guna memperoleh 
data yang aktual (Sugiyono, 2008). Pengukuran variabel menggunakan skala likert, mulai dari sangat tidak puas (1), tidak puas (2), cukup puas (3), puas (4), dan sangat puas (5).

Tahapan analisis data pada penelitian ini yaitu: (a) uji instrumen penelitian yang terdiri dari uji validitas dan uji reliabilitas, dan (b) analisis indeks kepuasan yang terdiri dari analisis indeks kepuasan, analisis gap kepuasan,dan analisis pemetaan kepuasan dengan diagram kartesius.

\section{HASIL DAN PEMBAHASAN}

\section{Uji Instrumen Penelitian}

\section{Uji Validitas}

Hasil uji validitas menunjukkan bahwa semua indikator dikatakan valid karena nilai signifikansi $<0,05$ dan $r_{\text {hitung }}$ lebih besar dari $r_{\text {tabel. }}$ Hasil uji validitas ini dapat dilihat pada tabel 3:

Tabel 3 Uji validitas

\begin{tabular}{|c|c|c|c|c|c|c|c|}
\hline \multirow{2}{*}{ Variabel } & \multirow{2}{*}{ Indikator } & \multicolumn{2}{|c|}{ Significant $(<0,05)$} & \multicolumn{2}{|c|}{$\mathbf{r}_{\text {hitung }}$} & \multirow[b]{2}{*}{$\mathbf{r}_{\text {tabel }}$} & \multirow{2}{*}{ Keterangan } \\
\hline & & Kinerja & Harapan & Kinerja & Harapan & & \\
\hline \multirow{4}{*}{ Tangibel } & $\mathrm{X} 1.1$ & 0,000 & 0,000 & 0,610 & 0,706 & 0,1966 & Valid \\
\hline & $\mathrm{X} 1.2$ & 0,000 & 0,000 & 0,585 & 0,814 & 0,1966 & Valid \\
\hline & $\mathrm{X} 1.3$ & 0,000 & 0,000 & 0,625 & 0,819 & 0,1966 & Valid \\
\hline & $\mathrm{X} 1.4$ & 0,000 & 0,000 & 0,621 & 0,784 & 0,1966 & Valid \\
\hline \multirow[t]{3}{*}{ Reliablility } & $\mathrm{X} 2.1$ & 0,000 & 0,000 & 0,848 & 0,858 & 0,1966 & Valid \\
\hline & $\mathrm{X} 2.2$ & 0,000 & 0,000 & 0,894 & 0,837 & 0,1966 & Valid \\
\hline & $\mathrm{X} 2.3$ & 0,000 & 0,000 & 0,857 & 0,873 & 0,1966 & Valid \\
\hline \multirow[t]{3}{*}{ Responsiveness } & X3.1 & 0,000 & 0,000 & 0,862 & 0,827 & 0,1966 & Valid \\
\hline & X3.2 & 0,000 & 0,000 & 0,864 & 0,896 & 0,1966 & Valid \\
\hline & $\mathrm{X} 3.3$ & 0,000 & 0,000 & 0,827 & 0,924 & 0,1966 & Valid \\
\hline \multirow[t]{4}{*}{ Assurance } & $\mathrm{X} 4.1$ & 0,000 & 0,000 & 0,801 & 0,714 & 0,1966 & Valid \\
\hline & $\mathrm{X} 4.2$ & 0,000 & 0,000 & 0,776 & 0,778 & 0,1966 & Valid \\
\hline & $\mathrm{X} 4.3$ & 0,000 & 0,000 & 0,799 & 0,845 & 0,1966 & Valid \\
\hline & $\mathrm{X} 4.4$ & 0,000 & 0,000 & 0,724 & 0,788 & 0,1966 & Valid \\
\hline \multirow[t]{4}{*}{ Empathy } & X5.1 & 0,000 & 0,000 & 0,789 & 0,777 & 0,1966 & Valid \\
\hline & X5.2 & 0,000 & 0,000 & 0,759 & 0,815 & 0,1966 & Valid \\
\hline & $\mathrm{X} 5.3$ & 0,000 & 0,000 & 0,688 & 0,824 & 0,1966 & Valid \\
\hline & X5.4 & 0,000 & 0,000 & 0,797 & 0,844 & 0,1966 & Valid \\
\hline
\end{tabular}

Sumber: Data primer yang diolah, 2019

\section{Uji Reliabilitas}

Hasil uji reliabilitas menunjukkan bahwa data dalam penelitian ini adalah reliabel karena semua dimensi memiliki nilai cronbach's alpha lebih dar 0,70. 
keunis Majalah Ilmiah - ISSN No 2302-9315 Vol. 8 No 2 Thn VIII Juli 2020

Tabel 4 Uji Reliabilitas

\begin{tabular}{|l|c|c|c|c|c|}
\hline \multirow{2}{*}{ Variabel } & \multirow{2}{*}{ Indikator } & \multicolumn{2}{|c|}{ Cronbach's Alpha } & \multirow{2}{*}{$\begin{array}{c}\text { Minimum } \\
\text { Standart }\end{array}$} & \multirow{2}{*}{ Keterangan } \\
\cline { 3 - 4 } & & Kinerja & Harapan & \\
\hline Tangible & $\mathrm{X} 1$ & 0,771 & 0,787 & 0,70 & Reliable \\
\hline Reliability & $\mathrm{X} 2$ & 0,834 & 0,818 & 0,70 & Reliable \\
\hline Responsiveness & $\mathrm{X} 3$ & 0,810 & 0,858 & 0,70 & Reliable \\
\hline Assurance & $\mathrm{X} 4$ & 0,779 & 0,792 & 0,70 & Reliable \\
\hline Empathy & $\mathrm{X} 5$ & 0,797 & 0,832 & 0,70 & Reliable \\
\hline
\end{tabular}

Sumber: Data primer yang diolah, 2019

\section{Analisis Kepuasan Nasabah}

\section{Analisis Indeks Kepuasan}

Analisis Indeks Kepuasan adalah analisis yang digunakan untuk mengetahui tingkat kepuasan nasabah secara menyeluruh dengan melihat tingkat kinerja dan tingkat harapan. Analisis indeks kepuasan nasabah dapat diukur dengan menggunakan langkah-langkah sebagai berikut:

1. Menentukan atribut produk yang menjadi alasan pembelian pelanggan.

2. Hitung rata-rata harapan untuk setiap atribut.

3. Hitung weighting factors dengan membagi rata-rata harapan dengan total rata-rata harapan tiap atribut.

4. Hitung rata-rata kinerja setiap atribut.

5. Hitung weighting score dengan mengalikan rata-rata kinerja untuk setiap faktor dengan weighting factors.

6. Hitung weighting average dengan menjumlahkan seluruh weighting score untuk setiap faktor.

7. Tentukan satisfaction index dengan membuat jenjang skala kepuasan dengan rumus (max-min) : jumlah jenjang skala.

Berdasarkan hasil uji indeks kepuasan nasabah pengguna layanan internet banking Bank Jateng Kantor Cabang Pati diketahui bahwa indeks kepuasan/ weighting average kualitas pelayanan mendapat nilai 4,219 yang berada diantara 3,43 - 4,23 yang berarti secara keseluruhan responden Puas terhadap kualitas pelayanan yang diberikan oleh Bank Jateng Kantor Cabang Pati.

\section{Uji Gap Kepuasan}

Uji gap kepuasan adalah membandingkan kinerja dan harapan dari tiap-tiap indikator. Suatu indikator dikatakan puas yaitu kinerja lebih besar dari harapan. Hal ini dikarenakan dapat terlihat dari kinerja suatu bank. 
keunis Majalah IImiah - ISSN No 2302-9315 Vol. 8 No 2 Thn VIII Juli 2020

Tabel 5 Perhitungan Uji Gap Kepuasan

\begin{tabular}{|c|c|c|c|c|c|}
\hline Variabel & Indikator & $\begin{array}{c}\text { Rata-rata } \\
\text { Kinerja }\end{array}$ & $\begin{array}{l}\text { Rata-rata } \\
\text { Harapan }\end{array}$ & Gap & Keterangan \\
\hline \multirow{4}{*}{$\begin{array}{l}\text { Bukti Fisik } \\
\text { (Tangible) }\end{array}$} & $X_{1.1}$ & 4,28 & 4,02 & 0,26 & Puas \\
\hline & $\mathrm{X}_{1.2}$ & 4,18 & 3,99 & 0,19 & Puas \\
\hline & $\mathrm{X}_{1.3}$ & 4,23 & 4,12 & 0,11 & Puas \\
\hline & $\mathrm{X}_{1.4}$ & 4,24 & 4,05 & 0,19 & Puas \\
\hline \multicolumn{2}{|l|}{ Jumlah } & 16,93 & 16.18 & 0,75 & Puas \\
\hline \multirow{3}{*}{$\begin{array}{l}\text { Kehandalan } \\
\text { (Reliability) }\end{array}$} & $X_{2.1}$ & 4,29 & 4,11 & 0,18 & Puas \\
\hline & $\mathrm{X}_{2.2}$ & 4,26 & 4,13 & 0,13 & Puas \\
\hline & $\mathrm{X}_{2.3}$ & 4,21 & 4,23 & $-0,02$ & Tidak Puas \\
\hline \multicolumn{2}{|l|}{ Jumlah } & 12,76 & 12,47 & 0,29 & Puas \\
\hline \multirow{3}{*}{$\begin{array}{l}\text { Daya Tanggap } \\
\text { (Responsiveness) }\end{array}$} & $X_{3.1}$ & 4,11 & 4,12 & $-0,01$ & Tidak Puas \\
\hline & $\mathrm{X}_{3.2}$ & 4,21 & 4,25 & $-0,04$ & Tidak Puas \\
\hline & $X_{3.3}$ & 4,13 & 4,24 & $-0,11$ & Tidak Puas \\
\hline \multicolumn{2}{|l|}{ Jumlah } & 12,45 & 12,61 & $-0,16$ & Tidak Puas \\
\hline \multirow{4}{*}{$\begin{array}{l}\text { Jaminan } \\
\text { (Assurance) }\end{array}$} & $\mathrm{X}_{4.1}$ & 4,09 & 4,06 & 0,03 & Puas \\
\hline & $\mathrm{X}_{4.2}$ & 4,20 & 4,03 & 0,17 & Puas \\
\hline & $\mathrm{X}_{4.3}$ & 4,22 & 4,02 & 0,20 & Puas \\
\hline & $\mathrm{X}_{4.4}$ & 4,16 & 3,88 & 0,28 & Puas \\
\hline \multicolumn{2}{|l|}{ Jumlah } & 16.67 & 15,99 & 0,68 & Puas \\
\hline \multirow{4}{*}{ Empati (Empathy) } & $\mathrm{X}_{5.1}$ & 4,32 & 4,01 & 0,31 & Puas \\
\hline & $\mathrm{X}_{5.2}$ & 4,31 & 4,09 & 0,22 & Puas \\
\hline & $\mathrm{X}_{5.3}$ & 4,26 & 4,02 & 0,24 & Puas \\
\hline & $X_{5.4}$ & 4,22 & 4,06 & 0,16 & Puas \\
\hline \multicolumn{2}{|l|}{ Jumlah } & 17,11 & 16.18 & 0,93 & Puas \\
\hline
\end{tabular}

Sumber: Data primer yang diolah, 2019

\section{Pemetaan Kepuasan dengan Diagram Kartesius}

Menurut Supranto (2006:241-242) diagram kartesius merupakan suatu bangun yang dibagi atas empat bagian yang dibatasi oleh dua buah garis yang berpotongan tegak lurus pada titik (X dan Y).

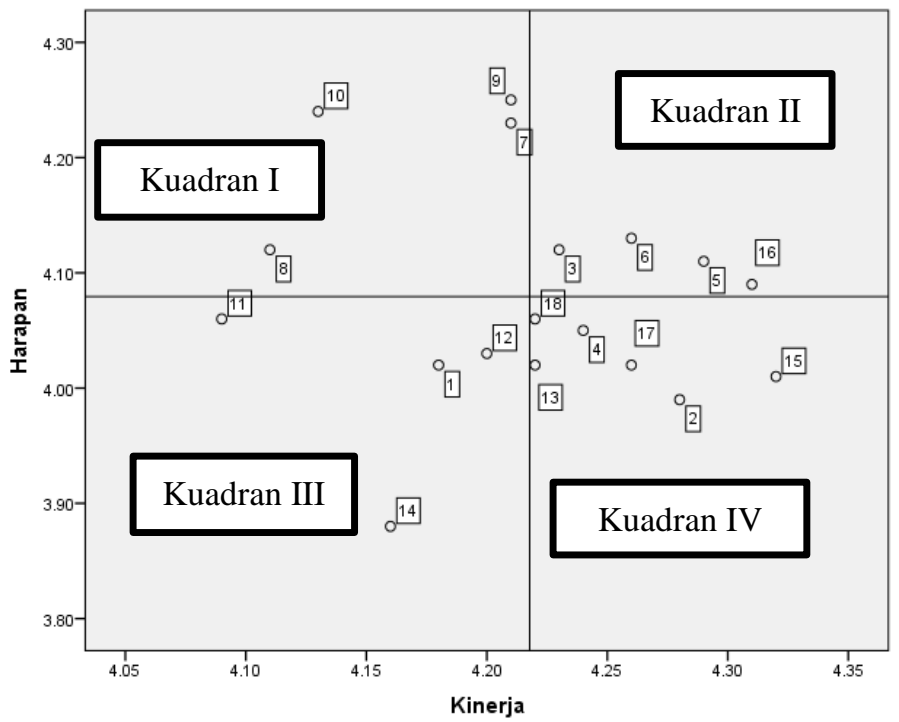

Sumber: Data primer yang diolah, 2019

Gambar 2 Diagram Kartesius 
Berdasarkan diagram kartesius di atas terlihat bahwa letak dari indikator-indikator yang mempengaruhi kepuasan nasabah pada pengguna ATM Bank Jateng KCP Kaligawe Semarang terbagi menjadi empat bagian. Adapun interpretasi dari diagram kartesius tersebut dapat dijelaskan sebagai berikut:

1. Kuadran I $($ Prioritas Utama $)=$ Attention

Kuadran I merupakan wilayah yang menjadi prioritas utama dalam pengembangan strategi pemasaran layanan internet banking Bank Jateng Kantor Cabang Pati. Wilayah ini memuat indikator yang dianggap penting oleh nasabah tetapi pelaksanaannya belum sesuai yang diharapkan. Adapun indikator-indikator yang termasuk dalam wilayah ini adalah sebagai berikut:

a. Akses layanan internet banking Bank Jateng lancar $\left(\mathrm{X}_{2.3}\right)$.

b. Petugas Bank Jateng tanggap dalam menangani keluhan nasabah internet banking $\left(\mathrm{X}_{3.1}\right)$.

c. Prosedur layanan call centre internet banking Bank Jateng jelas dan tidak berbelitbelit $\left(\mathrm{X}_{3.2}\right)$.

d. Adanya layanan khusus apabila terjadi masalah dengan internet banking Bank Jateng $\left(\mathrm{X}_{3.3}\right)$.

2. Kuadran II (Pertahankan) $=$ Be Happy

Kuadran II merupakan wilayah yang memuat indikator-indikator yang dianggap penting oleh nasabah dan pelaksanaannya sudah sesuai dengan harapan nasabah, sehingga pihak bank harus mempertahankan indikator yang terletak pada wilayah ini. Adapun indikator-indikator yang termasuk dalam wilayah ini adalah sebagai berikut:

a. Website internet banking Bank Jateng menyediakan bahasa yang mudah untuk dimengerti $\left(\mathrm{X}_{1.3}\right)$.

b. Informasi dalam website internet banking Bank Jateng akurat $\left(\mathrm{X}_{2.1}\right)$.

c. Setiap transaksi layanan internet banking Bank Jateng selalu menerima konfirmasi $\left(\mathrm{X}_{2.2}\right)$.

d. Menu help tersedia di website internet banking Bank Jateng untuk mempermudah pengguna internet banking $\left(\mathrm{X}_{5.2}\right)$.

3. Kuadran III (Prioritas Rendah) $=$ Don't Worry

Kuadran III merupakan wilayah yang memuat indikator-indikator yang tingkat harapannya di bawah rata-rata dan kinerja dari Bank Jateng Kantor Cabang Pati juga di bawah rata-rata. Hal ini sangat sesuai karena harapan nasabah sama dengan kinerja dari 
Bank Jateng Kantor Cabang Pati yang sama-sama tidak terlalu tinggi. Adapun indikatorindikator yang termasuk dalam wilayah ini adalah sebagai berikut:

a. Mudah untuk masuk pada portal website internet banking Bank Jateng ( $\left.\mathrm{X}_{1.1}\right)$.

b. Sistem internet banking Bank Jateng dilengkapi dengan keamanan yang canggih sehingga pihak bank menjamin kerahasiaan dalam transaksi $\left(\mathrm{X}_{4.1}\right)$.

c. Petugas call centre internet banking Bank Jateng memiliki sikap yang ramah dan $\operatorname{sopan}\left(\mathrm{X}_{4.2}\right)$.

d. Bank Jateng memberikan jaminan apabila terjadi kesalahan transaksi di internet banking $\left(\mathrm{X}_{4.1}\right)$.

4. Kuadran IV (Berlebihan $)=C u t$

Kuadran ini memuat indikator-indikator yang mempengaruhi kepuasan nasabah internet banking yang dinilai berlebihan dalam kinerjanya, hal ini terutama disebabkan karena nasabah menganggap tidak terlalu penting terhadap adanya faktor tersebut, akan tetapi pelaksanaannya dilakukan dengan baik sekali oleh perusahaan sehingga nasabah merasa puas dengan kinerja Bank Jateng Kantor Cabang Pati. Adapun indikator-indikator yang ada pada kuadran ini adalah:

a. Tampilan website internet banking Bank Jateng didesain secara jelas, menarik dan informatif $\left(\mathrm{X}_{1.2}\right)$.

b. Website internet banking Bank Jateng menyediakan iklan dan fitur-fitur yang jelas $\left(\mathrm{X}_{1.4}\right)$.

c. Kunci pengaman (password) internet banking Bank Jateng tidak mudah terlacak $\left(\mathrm{X}_{4.3}\right)$.

d. Call centre internet banking Bank Jateng melayani selama 24 jam $\left(\mathrm{X}_{5.1}\right)$.

e. $\quad$ Tersedianya kotak saran di website internet banking Bank Jateng $\left(\mathrm{X}_{5.3}\right)$.

f. $\quad$ Bank Jateng menangani masalah internet banking dengan baik $\left(\mathrm{X}_{5.4}\right)$.

\section{KESIMPULAN DAN SARAN}

\section{Kesimpulan}

Dalam penelitian tentang kepuasan nasabah atas kualitas layanan internet banking pada Bank Jateng Kantor Cabang Pati dapat diambil kesimpulan sebagai berikut:

1. Untuk Pengujian kualitas pelayanan nasabah internet banking Bank Jateng Kantor Cabang Pati, menggunakan dimensi kualitas pelayanan yang terdiri dari tangible (bukti fisik), reliability (kehandalan), responsiveness (daya tanggap), assurance (jaminan), dan empathy (empati). 
2. Berdasarkan hasil analisis kepuasan nasabah yang telah dilakukan, diketahui bahwa nasabah internet banking merasa puas dengan pelayanan yang diberikan oleh Bank Jateng Kantor Cabang Pati.

3. Berdasarkan uraian dan analisis yang telah dilakukan, dapat disimpulkan bahwa dalam meningkatkan kepuasan nasabah pengguna internet banking, diperlukan kebijakan yang dapat mempertahankan kepuasan. Kebijakan tersebut dapat dilakukan dengan cara memperbaiki indikator-indikator yang dianggap penting untuk nasabah, sehingga menjadi prioritas perusahaan dalam menjaga kualitas layanan kepada nasabah. Indikator tersebut dapat dilihat pada diagram kartesius kuadran A dan C.

\section{Implikasi Teoritis}

Implikasi teoritis pada penelitian ini didasarkan pada hasil uji gap kepuasan nasabah internet banking Bank Jateng Kantor Cabang Pati untuk indikator diambil hasil tertinggi untuk mendukung teori, dapat dijelaskan pada Tabel 6.

Tabel 6 Implikasi Manajerial

\begin{tabular}{|c|c|c|}
\hline Variabel & Indikator & Referensi Pendukung \\
\hline $\begin{array}{l}\text { Bukti Fisik } \\
\text { (Tangible) }\end{array}$ & $\begin{array}{l}\text { Mudah untuk masuk pada } \\
\text { portal website internet } \\
\text { banking Bank Jateng. }\end{array}$ & $\begin{array}{l}\text { Hasil penelitian ini mendukung teori } \\
\text { Lupiyoadi (2013:216) yang } \\
\text { menyatakan bahwa bukti fisik } \\
\text { merupakan penampilan dan } \\
\text { kemampuan sarana dan prasarana } \\
\text { fisik yang dapat diandalkan. }\end{array}$ \\
\hline $\begin{array}{l}\text { Kehandalan } \\
\text { (Reliability) }\end{array}$ & $\begin{array}{l}\text { Informasi dalam website } \\
\text { internet banking Bank } \\
\text { Jateng akurat. }\end{array}$ & $\begin{array}{l}\text { Hasil penelitian ini mendukung teori } \\
\text { Tjiptono dan Chandra (2007:133) } \\
\text { yang menyatakan bahwa kehandalan } \\
\text { merupakan kemampuan perusahaan } \\
\text { untuk memberikan layanan yang } \\
\text { akurat. }\end{array}$ \\
\hline $\begin{array}{r}\text { Daya } \mathrm{T} \\
\text { (Respon }\end{array}$ & $\begin{array}{l}\text { Petugas } \text { Bank Jateng } \\
\text { tanggap dalam menangani } \\
\text { keluhan nasabah internet } \\
\text { banking }\end{array}$ & $\begin{array}{l}\text { Hasil penelitian ini mendukung teori } \\
\text { Tjiptono dan Chandra (2007:134) } \\
\text { yang menyatakan bahwa daya } \\
\text { tanggap merupakan kemampuan } \\
\text { para karyawan untuk membantu } \\
\text { pelanggan. }\end{array}$ \\
\hline $\begin{array}{c}\text { Jaminan } \\
\text { (Assurance) }\end{array}$ & $\begin{array}{l}\text { Bank Jateng memberikan } \\
\text { jaminan apabila terjadi } \\
\text { kesalahan transaksi di } \\
\text { internet banking. }\end{array}$ & $\begin{array}{l}\text { Hasil penelitian ini mendukung teori } \\
\text { Tjiptono dan Chandra (2007:134) } \\
\text { yang menyatakan bahwa jaminan } \\
\text { merupakan kemampuan perusahaan } \\
\text { untuk menciptakan rasa aman bagi } \\
\text { para pelanggannya. }\end{array}$ \\
\hline Empati & $\begin{array}{l}\text { Menu help tersedia di } \\
\text { website internet banking } \\
\text { Bank Jateng untuk } \\
\text { mempermudah pengguna } \\
\text { internet banking. }\end{array}$ & $\begin{array}{l}\text { Hasil penelitian ini mendukung teori } \\
\text { Lupiyoadi (2013:217) yang } \\
\text { menyatakan bahwa empati } \\
\text { merupakan perhatian yang diberikan } \\
\text { pelanggan dengan berupaya } \\
\text { memahami keinginan konsumen. }\end{array}$ \\
\hline
\end{tabular}




\section{Implikasi Manajerial}

Implikasi manajerial ini dapat digunakan sebagai masukan untuk mengembangkan kebijakan-kebijakan dalam hal meningkatkan kepuasan nasabah atas layanan internet banking pada Bank Jateng Kantor Cabang Pati.

1. Kuadran I (Prioritas Utama)

Terdapat empat indikator pada kuadran I yaitu: $\mathrm{X}_{2.3}, \mathrm{X}_{3.1}, \mathrm{X}_{3.2}$, dan $\mathrm{X}_{3.3}$. Berdasarkan indikator-indikator yang terdapat pada kuadran I, jika dilihat dari uji gap kepuasan yang memiliki nilai gap tertinggi adalah indikator $\mathrm{X}_{3.1}$ sebesar -0,01 dan yang memiliki nilai gap terendah adalah $\mathrm{X}_{3.3}$ sebesar -0,11. Kuadran I merupakan prioritas utama yang harus ditingkatkan oleh Bank Jateng Kantor Cabang Pati, karena pada kuadran I harapan nasabah lebih tinggi daripada kinerja petugas. Oleh karena itu Bank Jateng Kantor Cabang Pati diharapkan dapat melakukan perbaikan secara terus-menerus sehingga performance variabel yang ada dalam kuadran ini akan meningkat.

2. Kuadran II (Pertahankan)

Terdapat empat indikator pada kuadran II yaitu: $\mathrm{X}_{1.3}, \mathrm{X}_{2.1}, \mathrm{X}_{2.2}$, dan $\mathrm{X}_{5.2}$. Berdasarkan indikator-indikator yang terdapat pada kuadran I, jika dilihat dari uji gap yang memiliki nilai gap tertinggi adalah indikator $\mathrm{X}_{5.2}$ sebesar 0,22 dan yang memiliki nilai gap terendah adalah $\mathrm{X}_{1.3}$ sebesar 0,11 . Kuadran II merupakan indikator yang harus dipertahankan, karena harapan nasabah yang tinggi seimbang dengan kinerja petugas yang tinggi. Oleh karena itu Bank Jateng Kantor Cabang Pati diharapkan dapat mempertahankan dan meningkatkan kinerja yang sudah bagus ini.

3. Kuadran III (Prioritas Rendah)

Terdapat empat indikator pada kuadran III yaitu: $\mathrm{X}_{1.1}, \mathrm{X}_{4.1}, \mathrm{X}_{4.2}$, dan $\mathrm{X}_{4.4}$. Berdasarkan indikator-indikator yang terdapat pada kuadran III, jika dilihat dari uji gap kepuasan yang memiliki nilai gap tertinggi adalah indikator $\mathrm{X}_{4.4}$ sebesar 0,28 dan yang memiliki nilai gap terendah adalah $\mathrm{X}_{4.1}$ sebesar 0,03. Indikator yang terdapat pada kuadran III adalah indikator yang memiliki harapan dan kinerja relatif rendah. Indikator ini perlu diperhatikan dan dikelola dengan serius, karena ketidakpuasan pelanggan pada umumnya berawal dari indikator-indikator ini. Oleh karena itu, Bank Jateng Kantor Cabang Pati diharapkan dapat memberikan perhatian lebih pada indikator-indikator yang terdapat pada kuadran III.

4. Kuadran IV (Berlebihan)

Terdapat enam indikator pada kuadran IV yaitu: $\mathrm{X}_{1.2}, \mathrm{X}_{1.4}, \mathrm{X}_{4.3}, \mathrm{X}_{5.1}, \mathrm{X}_{5.3}$, dan $\mathrm{X}_{5.4}$ Berdasarkan indikator-indikator yang terdapat pada kuadran IV, jika dilihat dari uji gap 
kepuasan yang memiliki nilai gap tertinggi adalah indikator $\mathrm{X}_{5.1}$ sebesar 0,31 dan yang memiliki nilai gap terendah adalah $\mathrm{X}_{1.2}$ dan $\mathrm{X}_{1.4}$ sebesar 0,19 . Indikator yang terdapat pada kuadran IV adalah indikator yang dianggap kurang penting oleh nasabah dan dirasakan terlalu berlebihan. Namun hal tersebut harus tetap dipertahankan dan menjadi perhatian dari Bank Jateng Kantor Cabang Pati.

\section{Keterbatasan Penelitian}

Penelitian ini hanya tentang kualitas layanan internet banking sehingga tidak bisa dipakai untuk kualitas layanan yang lain. Objek pada penelitian ini terbatas hanya pada Bank Jateng Kantor Cabang Pati dengan kriteria sampel tertentu. Sehingga penelitian mendatang diharapkan tidak hanya sebatas tentang kualitas layanan internet banking, dan hendaknya mampu mengambil sampel tidak hanya pada satu bank saja sehingga peneliti mampu membandingkan kepuasan nasabah pada satu bank dengan bank yang lainnya.

\section{DAFTAR PUSTAKA}

Bank Indonesia. 1998. Undang - Undang Republik Indonesia No. 10 Tahun 1998. Tentang Perbankan. Jakarta: Sinar Grafika.

Bank Indonesia. 2004. Surat Edaran No.6/18/DPNP Perihal Penerapan Manajemen Resiko Pada Aktifitas Pelayanan Jasa Bank Melalui Internet Banking. Jakarta: Bank Indonesia.

Erwin, Mutiara Erliza dan Susatyo Nugroho. 2015. "Analisis Kualitas Jasa Pelayanan Internet Banking Bank Bukopin dengan Metode Fuzzy E-Servqual, IPA, dan Usulan Perbaikan dengan Metode QFD”. Jurnal Industial Engineering. Volume 4, Nomor 1.

Ferdinand, Augusty. 2006. Metode Penelitian Manajemen. Semarang: Badan Penerbit Universitas Diponegoro.

Ghozali, Imam. 2006. Aplikasi Analisis Multivariate dengan Program SPSS Edisi 4. Semarang: Badan Penerbit Universitas Diponegoro.

Ghozali, Imam. 2018. Aplikasi Analisis Multivariate dengan Program IBM SPSS 25 Edisi 9. Semarang: Badan Penerbit Universitas Diponegoro.

Heryanto, Nicholas dan Ahmad H. Sutawidjaya. 2017. “Analisis Kualitas Layanan Internet Banking dengan Menggunakan Metode E-SERVQUAL pada Bank XYZ”. Jurnal Manajemen dan Bisnis. Volume 1, Nomor 3.

Huda, Ahmad Nurul dan Sri Wahyuni. 2013. "Analisis Pengaruh Kualitas Layanan Internet Banking dan Tingkat Kepuasan Terhadap Loyalitas Nasabah pada PT Bank Rakyat 
Indonesia (Persero) Tbk Kantor Cabang Pembantu Jamsostek Jakarta. Jurnal Business \& Management Review.

Jogiyanto. 2018. Metodologi Penelitian Bisnis. Yogyakarta: BPFE Yogyakarta.

Kasmir. 2004. Bank dan Lembaga Keuangan Lainnya. Jakarta: PT. RajaGrafindo Persada. Kasmir. 2007. Dasar-dasar Perbankan. Jakarta: PT. RajaGrafindo Persada.

Kasmir. 2012. Manajemen Perbankan. Jakarta: PT. RajaGrafindo Persada.

Kotler, Philip. 2008. Manajemen Pemasaran, Edisi Milenium 1. Jakarta: PT Prenhallindo. Lupiyoadi, Rambat. 2013. Manajemen Pemasaran Jasa Berbasis Kompetensi (Edisi 3). Jakarta: Salemba Empat

Lupiyoadi dan A Hamdani. 2008. Manajemen Pemasaran Jasa, Edisi 2. Jakarta: Salemba Empat.

Majalah Infobank. Mei 2018. The Best Bank Service Excellent 2018.

Marzuki. 2000. Metodologi Riset. Yogyakarta: PT. Prasetya Widia Pratama.

Simamora, Bilson. 2004. Riset Pemasaran. Jakarta: Gramedia Pustaka Utama.

Sudirman, I Made S. A. Santhika dan I Gusti Agung Ketut Gede Suasana. 2018. "Pengaruh Kualitas Layanan Online Terhadap Kepuasan, Komitmen, dan Loyalitas Nasabah Internet Banking di Kota Denpasar”. Jurnal Inovasi Bisnis dan Manajemen Indonesia. Volume 1, Nomor 4, September 2018.

Sugiyono. 2013. Metode Penelitian Kuantitatif Kualitatif dan R\&D. Bandung: Alfabeta Sulistyorini, Utami Tri. 2006. Strategi Pemasaran Jasa Pada Lembaga Keuangan. Semarang: Penerbit Polines.

Supardi. 2005. Metodologi Penelian Ekonomi \& Bisnis. Yogyakarta: UII Pers.

Supranto, Johannes. 2003. Metode Riset Aplikasinya dalam Pemasaran. Jakarta: PT. Rineka Cipta.

Tim Penyusunan Pedoman Tugas Akhir. 2014. Pedoman Penyusunan tugas Akhir Jurusan Akuntansi Politeknik Negeri Semarang. Semarang: Politeknik Negeri Semarang. Tjiptono, Fandy. 2004. Manajemen Jasa. Yogyakarta: ANDI. 